Review

\title{
Suicidality in Borderline Personality Disorder
}

Joel Paris *

Institute of Community and Family Psychiatry, McGill University, 4333 chemin de la cote ste. Catherine, Montreal, QC H3T1E4, Canada

Received: 9 January 2019; Accepted: 15 May 2019; Published: 28 May 2019

Abstract: Borderline personality disorder (BPD) is associated with suicidal behaviors and self-harm. Up to $10 \%$ of BPD patients will die by suicide. However, no research data support the effectiveness of suicide prevention in this disorder, and hospitalization has not been shown to be useful. The most evidence-based treatment methods for BPD are specifically designed psychotherapies.

Keywords: suicide suicidality personality disorder; borderline personality disorder; self-harm

\section{Introduction}

This review is based on a search with the key words "borderline personality disorder" and "suicide or suicidality" in MEDLINE and PsycINFO of all articles since 2000 (along with some important older articles). This review focuses on articles that are most relevant to the following questions:

(1) What suicidal behaviors are seen in patients with borderline personality disorder (BPD), and what is their motivation?

(2) What is the risk for death by suicide in BPD?

(3) Is there evidence for the value of hospitalizing suicidal BPD patients?

(4) What are the most evidence-based treatments for suicidal BPD patients?

\section{Suicidal Behaviors in BPD}

As defined by the DSM-5 [1] and by the ICD-11 [2], personality disorders (PDs) are characterized by abnormal patterns of inner experience and behavior. These affect cognition, emotion, interpersonal functioning, impulse control, are inflexible and pervasive, lead to clinically significant distress or impairment, are stable and of long duration, and have an onset in adolescence or early adulthood. Personality disorders are common in practice, and can be found, above and beyond other diagnoses, in up to $45 \%$ of all outpatients [3]. Of these, BPD is by far the most researched category due to the clinical challenges it presents.

BPD is associated with a wide range of psychopathology, including unstable mood, impulsive behaviors, as well as unstable interpersonal relationships [1]. BPD patients have a mean of three lifetime suicide attempts, mostly by overdose [4].

Self-harm behaviors (i.e., non-suicidal self-injury) (NSSI) [5], are also common in BPD. NSSI usually presents as superficial cuts to the wrists and arms. However, NSSI is not suicidal in intent; BPD patients have problems with emotional regulation and cut themselves addictively to reduce painful inner states [6]. Cutting relieves emotional tension, but does not reflect a wish to die [7].

While drug overdoses can sometimes be life threatening, these behaviors vary greatly in nature and intent. They usually occur following stressful life events, and patients describe their motivation as a wish to escape [7]. Most incidents reflect ambivalent motivation, involving small quantities of medication and/or calling significant others for help. Even when potentially fatal overdoses occur, patients often contact people who are in a position to intervene. 
It has long been established that suicide attempters and completers are separate but overlapping populations [8]. In a large-scale follow-up of attempters seen in an emergency room (ER), only about $3 \%$ eventually died by suicide [9]. Most repetitive attempts occur in young women, and decrease with time [10].

\section{Death by Suicide in BPD Patients}

Follow-back research has found that suicide occurs in up to $10 \%$ of BPD cases [11,12]. However, lower rates $(3 \%-6 \%)$ have been reported in prospectively followed cohorts [13-15]. These discrepancies could reflect less-severe suicidality in patients who agree to be followed in research studies.

By and large, suicides in BPD occur later in the course of the illness and follow long courses of unsuccessful treatment [16]. A 15-year follow-back study found that the mean age at suicide to be 30 [12], while a 27-year follow-up reported a mean age of 37, with a standard deviation of 10 [11]. Thus, patients are not at their highest risk of suicide when they are young and frequent visitors to the ER.

Even so, patients with BPD do kill themselves. Psychological autopsy methods, which involve post-mortem interviews with families, have examined the frequency of this diagnosis in death by suicide [17-19]. In these studies, PDs were present in about half of the cases under the age of 35, with BPD being the most common category.

A meta-analysis by Pompili et al. [20] noted that suicidality is "more alarming" in young people, with a high level of suicidal behaviors. Yet the great majority of BPD patients eventually improve over time [16], and those who die by suicide tend to be those who fail to recover.

Males with BPD have a different pattern. Nearly a third of youth suicides, most of whom are male, can be diagnosed with BPD by psychological autopsy [17]. Other studies of BPD patients who died by suicide also show a preponderance of males [21]. Few of these patients were in treatment at the time of their death.

\section{Hospitalization for Suicidality in BPD Patients}

Many BPD patients have courses of treatment marked by multiple failed suicide attempts. These treatments are associated with multiple trials of psychotherapy, multiple prescriptions, repeated emergency room visits, and hospitalization for suicide attempts and threats [22]. Yet the research literature on the management of suicidality in BPD does not provide evidence-based guidelines for the prevention of death by suicide [23].

It has long been known that clinicians lack algorithms that can predict a fatal outcome in major mental disorders with any accuracy. As summarized in an article in The Lancet [24], in spite of a large body of research on suicide prediction, there is still no effective algorithm that can be used in practice to predict suicide. At best, clinicians are left with guidelines that may be commonsensical, but that lack empirical support.

However, the absence of evidence for prevention has not changed practice in managing BPD. Specifically, many patients are admitted to hospital when they attempt or threaten suicide. It is understandable that clinicians want to err on the safe side, but the absence of controlled data prevents us from concluding that hospital stays offer an effective method of suicide prevention. Admission for suicidal threats was recommended by the American Psychiatric Association guidelines for the treatment of BPD [25]. However, these guidelines, which have never been updated, were based on clinical opinion, and not on data showing that hospital admission has a preventive effect.

Repeated hospitalization for suicidal threats and attempts can also be counter-productive, since it interferes with out-patient treatment, and makes it impossible for patients to remain in the workplace [26-28]. It can also lead to a kind of "regression", with an increase of symptoms based on the behavioral reinforcement of suicidal behavior. Linehan [6] recommends not admitting patients for suicidality beyond an overnight hold in a crisis. 


\section{Evidence-Based Treatments for BPD}

We now know that well-structured ambulatory treatment, using methods specifically developed for BPD, is an effective intervention for most BPD patients. The most extensively investigated treatment is dialectical behavior therapy (DBT) [6], whose efficacy has been confirmed by randomized clinical trials $[29,30]$. The main outcomes are reductions in overdoses, in emergency room visits for suicidality, reduced frequency of self-harm, and reduced hospital admissions. DBT specifically aims to modify the regulation of emotion, teaching patients how to regulate negative emotions in ways other than cutting or overdosing [6].

Several other psychotherapy methods have also been tested in randomized clinical trials: mentalization-based therapy [31,32]; transference-focused psychotherapy [33]; schema-focused therapy [34]; and standard cognitive therapy [35].

All these methods target the affective instability (emotion dysregulation) that characterizes BPD [6,36], as well as impulsivity [37]. Emotion dysregulation accompanied by a lack of control over impulses makes patients more likely to turn to suicidal actions, and the frequency of suicide attempts is strongly related to these traits [10]. Thus, all methods of psychotherapy attempt to teach patients to stand outside their emotions, to self-reflect before acting on them, and to develop a better understanding of interpersonal conflict.

By and large, all psychological treatments that are well-structured and specifically designed for BPD patients are superior to standard clinical management. A Cochrane report [38] as well as a systematic meta-analysis [39] have summarized this evidence, supporting the conclusion that specific forms of psychotherapy for BPD are efficacious. These methods are usually provided in out-patient settings, and do not require hospital admission. As noted by Zanarini [40], BPD patients need to "get a life", which means therapists must work actively to involve them with life goals, such as career and social networks.

In contrast, the efficacy of pharmacological agents in BPD is not well established. No clinical trials have documented remission of the disorder with successful drug treatment, and a Cochrane report did not find sufficient evidence to prescribe any drug for patients with BPD [41]. Recent research has also shown that anticonvulsant mood stabilizers are not efficacious [42]. There is some evidence for the use of antipsychotics for short periods [43]. A similar conclusion has been reached by the UK National Institute on Clinical Excellence [44]. Unfortunately, it has long been observed that most BPD patients are often on multiple medications, including antidepressants, mood stabilizers, and/or neuroleptics [22], and this practice does not seem to have changed. These interventions do not require hospital admission. There is also no evidence that pharmacological regimes are effective for suicide prevention.

\section{Implications for Practice}

One of the most unique aspects of BPD is chronic suicidal ideation [27]. Patients with mood disorders can be suicidal when depressed, but usually put these ideas aside when they go into remission. In contrast, BPD patients may consider suicide on a daily basis for months to years, and only go into remission much later. Suicidal ideas will vary in intensity over time, waxing when life events are stressful, and waning when they are not.

Yet by themselves, suicidal thoughts are too common to be useful in predicting suicidal actions. But while patients with suicidal behaviors have a statistically higher risk, one cannot predict who is most likely to die by suicide. Deaths by suicide are rare events relative to attempts, which is why large-scale follow-up studies have found that algorithms based on risk factors fail to predict who will die by suicide [45,46]. The problem is false positives (patients who fit a profile but never kill themselves).

Most patients with BPD, despite having suicidal thoughts for long periods of time and multiple suicide attempts, never kill themselves. Thus, the level of alarm created by patients with BPD who present in clinics and ERs with suicidal ideas is not necessarily justified, even when threats are dramatic 
or blood-curdling. Clinicians need to work on making these patents more functional, and should not be distracted from these therapeutic tasks by suicidality.

Needless to say, chronic suicidality can be draining for therapists, and no one wants to lose a patient in this way. Yet in BPD, suicidality "goes with the territory" [47], and most patients cannot be treated without accepting a calculated risk [48]. Moreover, recommending ER visits and hospitalization reinforces the very behaviors they are designed to treat [6].

Hospitalization has not been supported by evidence, and when suicidality is chronic, admission to hospital provides only temporary relief; most patients continue to have suicidal ideas after discharge. While some research describes intensive treatment in hospital [49], similar programs could be offered on an out-patient basis. To avoid the harm of repetitive admissions, one might prefer day treatment, which offers the advantages of admission (intensive treatment by an experienced team) without its disadvantages, and has some supporting evidence for its efficacy [31]. Unfortunately, day programs usually have waiting lists and are not useful in a crisis.

In practice, BPD patients are commonly held in ERs (or admitted to wards) when they threaten suicide, cut themselves, or overdose. These choices are partly determined by a fear of litigation. However, to minimize the risk of lawsuits, clinicians can ensure careful record keeping, consult frequently with colleagues, and get families involved early on in treatment [50].

Based on current evidence, it is reasonable to conclude that we should treat suicidal patients with BPD on an out-patient basis using specialized forms of psychotherapy. Psychopharmacology remains adjunctive and optional. Hospital admission can be justified by either a near-fatal attempt (requiring a re-evaluation), or a micro-psychotic episode (requiring pharmacological intervention) [27]. Since we have no firm evidence that death by suicide in BPD can be prevented, we should focus on providing existing evidence-based psychological treatments designed for this challenging population.

Funding: This research received no external funding.

Conflicts of Interest: The authors declare no conflicts of interest.

\section{References}

1. American Psychiatric Association. Diagnostic and Statistical Manual of Mental Disorders, 5th ed.; Text Revision; American Psychiatric Press: Washington DC, USA, 2013.

2. World Health Organization. International Classification of Diseases, 11th ed.; World Health Organization: Geneva, Switzerland, 2018.

3. Zimmerman, M.; Rothschild, L.; Chelminski, I. The prevalence of DSM-IV personality disorders in psychiatric outpatients. Am. J. Psychiatry 2005, 162, 1911-1918. [CrossRef]

4. Soloff, P.H.; Lynch, K.G.; Kelly, T.M.; Malone, K.M.; Mann, J.J. Characteristics of suicide attempts of patients with major depressive episode and borderline personality disorder: A comparative study. Am. J. Psychiatry 2000, 157, 601-608. [CrossRef] [PubMed]

5. Nock, M.K.; Favazza, A. Nonsuicidal self-injury: Definition and classification. In Understanding Nonsuicidal Self- Injury: Origins, Assessment, and Treatment; Nock, M.K., Ed.; American Psychological Association: Washington, DC, USA, 2009; pp. 9-18.

6. Linehan, M.M. Cognitive Behavioral Therapy of Borderline Personality Disorder; Guilford: New York, NY, USA, 1993.

7. Brown, M.Z.; Comtois, K.A.; Linehan, M.M. Reasons for suicide attempts and nonsuicidal self-injury in women with borderline personality disorder. J. Abnorm. Psychol. 2002, 111, 198-202. [CrossRef]

8. Beautrais, A.L. Suicides and serious suicide attempts: Two populations or one? Psychol. Med. 2001, 31, 837-845. [CrossRef] [PubMed]

9. Hawton, K.; Zahl, D.; Weatherall, R. Suicide following deliberate self-harm: Long-term follow-up of patients who presented to a general hospital. Br. J. Psychiatry 2003, 182, 537-542. [CrossRef] [PubMed]

10. Paris, J. The Treatment of Borderline Personality Disorder, 2nd ed.; Guilford: New York, NY, USA, 2019.

11. Paris, J.; Zweig-Frank, H. A twenty-seven year follow-up of borderline patients. Compr. Psychiatry 2001, 42, 482-487. [CrossRef]

12. Stone, M.H. The Fate of Borderline Patients; Guilford: New York, NY, USA, 1990. 
13. Gunderson, J.G.; Stout, R.L.; McGlashan, T.H.; Shea, T.; Morey, L.C.; Grilo, C.M.; Zanarini, M.C.; Yen, S.; Markowitz, J.C.; Sanislow, C.; et al. Ten-year course of Borderline Personality Disorder: Psychopathology and function from the Collaborative Longitudinal Personality Disorders Study. Arch. Gen. Psychiatry 2011, 68, 827-837. [CrossRef] [PubMed]

14. Zanarini, M.C.; Frankenburg, F.; Reich, B.; Fitzmaurice, G. Attainment and stability of sustained symptomatic remission and recovery among borderline patients and Axis II comparison subjects: A 16-year prospective followup study. Am. J. Psychiatry 2012, 169, 476-483. [CrossRef]

15. Temes, C.M.; Frankenburg, F.; Fitzmaurice, G.; Zanarini, M.C. Deaths by suicide and other causes among patients with borderline personality disorder and personality-disordered comparison subjects over 24 years of prospective follow-up. J. Clin. Psychiatry 2019, in press. [CrossRef]

16. Paris, J. Personality Disorders Over Time; American Psychiatric Press: Washington, DC, USA, 2003.

17. Lesage, A.D.; Boyer, R.; Grunberg, F.; Morisette, R.; Vanier, C.; Morrisette, R.; Ménard-Buteau, C.; Loyer, M. Suicide and mental disorders: A case control study of young men. Am. J. Psychiatry 1994, 151, 1063-1068.

18. Hunt, I.M.; Kapur, N.; Robinson, J.; Shaw, J.; Flynn, S.; Bailey, H.; Meehan, J.; Bickley, H.; Burns, J.; Appleby, L.; et al. Suicide within 12 months of mental health service contact in different age and diagnostic groups: National clinical survey. Br. J. Psychiatry 2006, 188, 135-142. [CrossRef] [PubMed]

19. Tidemalm, D.; Elofsson, S.; Stefansson, C.-G.; Waern, M.; Runeson, B. Predictors of suicide in a community-based cohort of individuals with severe mental disorder. Soc. Psychiatry Psychiatry Epidemiol. 2005, 40, 595-600. [CrossRef] [PubMed]

20. Pompili, M.; Girardi, P.; Ruberto, A.; Tatarelli, R. Suicide in borderline personality disorder: A meta-analysis. Nord. J. Psychiatry 2005, 59, 319-324. [CrossRef] [PubMed]

21. McGirr, A.; Paris, J.; Lesage, A.; Renaud, J.; Turecki, G. Risk factors for suicide completion in borderline personality disorder: A case-control study of cluster B comorbidity and impulsive aggression. J. Clin. Psychiatry 2007, 68, 721-729. [CrossRef]

22. Zanarini, M.C.; Frankenburg, F.R.; Khera, G.S.; Bleichmar, J. Treatment histories of borderline inpatients. Compr. Psychiatry 2001, 42, 144-150. [CrossRef]

23. Goodman, M.; Roiff, T.; Oakes, A.H.; Paris, J. Suicidal risk and management in Borderline Personality Disorder. Curr. Psychiatry Rep. 2012, 14, 79-85. [CrossRef] [PubMed]

24. Turecki, G.; Brent, D. Suicide and suicidal behavior. Lancet 2016, 387, 19-25. [CrossRef]

25. Oldham, J.M.; Gabbard, G.O.; Goin, M.K.; Gunderson, J.; Soloff, P.; Spiegel, D.; Stone, M.; Phillips, K.A. Practice guideline for the treatment of Borderline Personality Disorder. Am. J. Psychiatry 2001, 158, 1-52.

26. Gunderson, J.G. Borderline Personality Disorder: A Clinical Guide, 2nd ed.; American Psychiatric Press: Washington, DC, USA, 2008.

27. Paris, J. Half in Love with Death: The Meaning of Chronic Suicidality; Laurence Erlbaum: Mahwah, NJ, USA, 2006.

28. Paris, J. Stepped Care for Borderline Personality Disorder; Academic Press: New York, NY, USA, 2017.

29. Linehan, M.M.; Armstrong, H.E.; Suarez, A.; Allmon, D.; Heard, H. Cognitive behavioral treatment of chronically parasuicidal borderline patients. Arch. Gen. Psychiatry 1991, 48, 1060-1064. [CrossRef] [PubMed]

30. Linehan, M.M.; Comtois, K.A.; Murray, A.M.; Brown, M.Z.; Gallop, R.J.; Heard, H.L.; Korslund, K.E.; Tutek, D.A.; Reyonolds, S.K.; Lindenboim, N. Two-year randomized controlled trial and follow-up of dialectical behavior therapy vs therapy by experts for suicidal behaviors and borderline personality disorder. Arch. Gen. Psychiatry 2006, 63, 757-766. [CrossRef] [PubMed]

31. Bateman, A.; Fonagy, P. Effectiveness of partial hospitalization in the treatment of borderline personality disorder: A randomized controlled trial. Am. J. Psychiatry 1999, 156, 1563-1569. [CrossRef] [PubMed]

32. Bateman, A.; Fonagy, P. Randomized controlled trial of out-patient mentalization-based treatment versus structured clinical management for borderline personality disorder. Am. J. Psychiatry 2009, 166, 1355-1364. [CrossRef] [PubMed]

33. Clarkin, J.F.; Levy, K.N.; Lenzenweger, M.F.; Kernberg, O.F. Evaluating three treatments for borderline personality disorder: A multiwave study. Am. J. Psychiatry 2007, 164, 1-8. [CrossRef]

34. Giesen-Bloo, J.; Van Dyck, R.; Spinhoven, P.; Van Tilburg, W.; Dirksen, C.; Van Asselt, T.; Kremers, I.; Nadort, M.; Arntz, A. Outpatient psychotherapy for borderline personality disorder: Randomized trial of schema-focused therapy vs. transference-focused psychotherapy. Arch. Gen. Psychiatry 2006, 63, 649-658. [CrossRef] 
35. Davidson, K.; Norrie, J.; Tyrer, P.; Gumley, A.; Tata, P.; Murray, H. The effectiveness of cognitive behavior therapy for borderline personality disorder: Results from the borderline personality disorder study of cognitive therapy [BOSCOT] trial. J. Personal. Disord. 2006, 20, 450-465. [CrossRef]

36. Koenigsberg, H.W.; Harvey, P.D.; Mitropoulou, V.; Schmeidler, J.; New, A.S.; Goodman, M.; Silverman, J.M.; Serby, M.; Schopick, F.; Siever, L. Characterizing affective instability in borderline personality disorder. Am. J. Psychiatry 2002, 159, 784-788. [CrossRef]

37. Crowell, S.E.; Beauchaine, T.P.; Linehan, M.M. A biosocial developmental model of borderline personality: Elaborating and extending Linehan's theory. Psychol. Bull. 2009, 135, 495-510. [CrossRef]

38. Stoffers-Winterling, J.M.; Völlm, B.A.; Rücker, G.; Timmer, A.; Huband, N.; Lieb, K. Psychological interventions for borderline personality disorder. Cochrane Library 2012. [CrossRef]

39. Cristea, I.A.; Gentilla, C.; Cotet, C.D.; Palomba, D.; Barbui, C.; Cuijpers, P. Efficacy of psychotherapies for Borderline Personality Disorder: A systematic review and meta-analysis. JAMA Psychiatry 2017, 74, 319-328. [CrossRef] [PubMed]

40. Zanarini, M.C. Psychotherapy of borderline personality disorder. Acta Psychiatry Scand. 2009, 120, $373-377$. [CrossRef] [PubMed]

41. Binks, C.A.; Fenton, M.; McCarthy, L.; Lee, T.; Adams, C.E.; Duggan, C. Pharmacological interventions for people with borderline personality disorder. Cochrane Database Syst. Rev. 2012, 1, CD005653.

42. Crawford, M.; Sanatinia, R.; Barrett, B.M.; Cunningham, G. The clinical effectiveness and cost-effectiveness of lamotrigine in borderline personality disorder: A randomized placebo-controlled trial. Am. J. Psychiatry 2018, 175, 576-580. [CrossRef]

43. Black, D.W.; Zanarini, M.C.; Ronine, A.; Shaw, M.; Allen, J.; Schulz, S.C. Comparison of low and moderate dosages of extended-release quetiapine in Borderline Personality Disorder: A randomized, double-blind, placebo-controlled trial. Am. J. Psychiatry 2014, 171, 1174-1182. [CrossRef] [PubMed]

44. National Institutes of Clinical Excellence. Guidelines for the Treatment of Borderline Personality Disorder. 2009. Available online: http://www.nice.org.uk/guidance/index.jsp?action=byID\&o=11651 (accessed on 10 May 2018).

45. Goldstein, R.B.; Black, D.W.; Nasrallah, A.; Winokur, G. The prediction of suicide. Arch. Gen. Psychiatry 1991, 48, 418-422. [CrossRef]

46. Pokorny, A.D. Prediction of suicide in psychiatric patients: Report of a prospective study. Arch. Gen. Psychiatry 1982, 40, 249-257. [CrossRef]

47. Schwartz, D.A.; Flinn, D.E.; Slawson, P.F. Treatment of the suicidal character. Am. J. Psychiatry 1974, 28, 194-207. [CrossRef]

48. Maltsberger, J.T. Calculated risk taking in the treatment of suicidal patients: Ethical and legal problems. Death Stud. 1994, 18, 439-452. [CrossRef]

49. Fowler, J.C.; Clapp, J.D.; Madan, A.; Allen, J.G.; Frueh, C.; Fonagy, P.; Oldham, J.M. A naturalistic longitudinal study of extended inpatient treatment for adults with borderline personality disorder: An examination of treatment response, remission and deterioration. J. Affect. Disord. 2018, 235, 323-331. [CrossRef] [PubMed]

50. Gutheil, T.G. Suicide and suit: Liability after self-destruction. In Suicide and Clinical Practice; Jacobs, D., Ed.; American Psychiatric Press: Washington, DC, USA, 1992; pp. 147-167.

(C) 2019 by the author. Licensee MDPI, Basel, Switzerland. This article is an open access article distributed under the terms and conditions of the Creative Commons Attribution (CC BY) license (http://creativecommons.org/licenses/by/4.0/). 